\title{
Energy modellers should explore extremes more systematically in scenarios
}

David L. McCollum ${ }^{1,2^{*}}$, Ajay Gambhir ${ }^{3}$, Joeri Rogelj ${ }^{3,4}$, Charlie Wilson ${ }^{4,5}$

${ }^{1}$ Electric Power Research Institute, Palo Alto, California, USA

${ }^{2}$ Howard H. Baker Jr. Center for Public Policy, University of Tennessee, Knoxville, Tennessee, USA

${ }^{3}$ Grantham Institute for Climate Change and the Environment, Imperial College, London, United Kingdom

${ }^{4}$ International Institute for Applied Systems Analysis, Laxenburg, Austria

${ }^{5}$ Tyndall Centre for Climate Change Research, University of East Anglia, Norwich, United Kingdom

“Corresponding author (dmccollum@epri.com)

Scenarios are the primary tool for examining how current decisions shape the future, but the future is affected as much by out-of-ordinary extremes as by generally expected trends. Energy modellers can study extremes both by incorporating them directly within models and by using complementary off-model analyses. 
Extremes come in many forms: wars, weather events, technological innovation, social activism, financial shocks, and swings in political ideology, among others. While often unpredictable, we can be certain that, at some point or another, they will come. Yet, the most prominently used energy models for informing national and international energy and climate policies are known to be limited in their ability, and appetite, to grapple with the out-of-ordinary. These models have many strengths, but, perhaps surprising to some, they generally do not allow for a deep exploration of unexpected events, drivers of change, and outcomes, even if these occurrences can push society towards wholly new equilibria. Current energy models are generally incapable of endogenously generating emergent phenomena, such as the invention of brand-new technologies or a new wave of social activism ${ }^{1,2}$. For these reasons, mainstream modelling practices potentially understate the significance that extremes could have in energy scenarios. This, we contend, is a major problem, given the role extremes will surely play in shaping the energy system and its myriad social, economic, political, and environmental impacts going forward. Here we comment on how the construction and application of energy models in scenarios research could be strengthened to better account for extremes.

\section{Extremes in energy systems models}

Extremes relevant to energy modelling and scenarios research include events, drivers, and outcomes (see Box) that are out of the ordinary and highly impactful in one or more of the following ways: geographically, technologically, environmentally, sociodemographically, economically, financially, politically, or institutionally4,5. 'Out of the 
ordinary' can simultaneously encompass both objective and subjective elements, and therefore can be interpreted either quantitatively (i.e., at the tails of a probabilistic distribution) or qualitatively (i.e., based on people's perceptions and experiences).

Categories of extremes relevant to energy modelling and scenarios research.

\section{Category 1: Transient events}

Events that might be considered out of the ordinary in the 'statistically low probability of occurrence' sense. These are events that may be anticipated but not necessarily well planned for. They could therefore be disruptive (whether singularly or as a cascading series). Such events would typically be short-term in nature.

Examples: weather events at the far edges of the 'normal' range; or a sudden and widespread financial and economic meltdown, like the sub-prime mortgage crisis of 2007-2008

\section{Category 2: Disruptive drivers}

Mega-trends that might be considered out of the ordinary in the "beyond common perceptions of a realistic future' sense. While the rudiments of such drivers may currently be anticipated, at least by some, the speed and scale at which they accelerate change may not be. Therefore, they would almost certainly be disruptive.

Examples: mass automation of service and manufacturing jobs at a rate much faster than currently anticipated; or the disentangling of deep-rooted economic and political alliances, like with Brexit and the China-US trade wars 


\section{Category 3: Unexpected outcomes}

Eventualities that might be considered out of the ordinary in the 'not even on the radar' sense - sometimes referred to as 'black swans'. These outcomes would be unanticipated, and in many cases they would be disruptive. Diverging so fundamentally from the status quo, they could push society to states where it has never been, or ever imagined being.

Examples: past surprises like prolonged wars spurred by terrorism; the forceful occupation of nation-states by others; re-emergence of nationalism; the seemingly irreparable fracturing of democratic institutions and political discourse by media; new discoveries in science, engineering, and medicine that redefine what is considered feasible

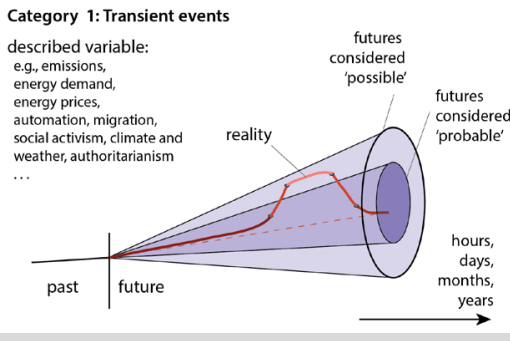

Category 2: Disruptive drivers

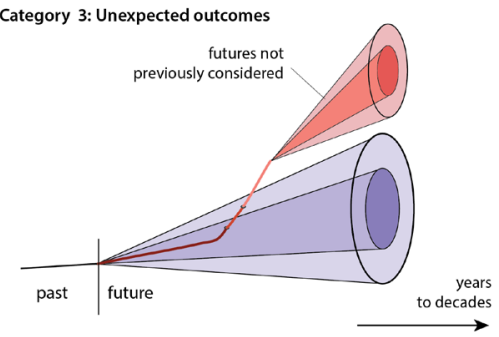

In the case of drivers and outcomes, the underlying forces of change generally build over longer periods of time. The effects of transient events may be long-lived as well, even if their unique feature is that they seemingly appear 'out of nowhere' (for example, the 2011 tsunami in Japan and its lasting ramifications for the global nuclear power industry). In other words, in general, events can transpire quite suddenly (i.e., over the 
short term: days to months to years) whereas drivers/outcomes are more accumulative (i.e., long term: years to decades) in nature.

\section{Modeller capacity to explore extremes}

Given the above categorisation of extremes, the next logical question is whether energy models are properly set up to handle the out-of-ordinary. At this point we should clarify that here we are specifically referring to the energy research communities concerned with modelling long-term, whole-systems dynamics in future scenarios, which primarily includes the integrated assessment (IAM) and energy-economy-environmentengineering (4E) modelling communities. For simplicity, we group the models from these communities together and call them generically 'energy models'. Admittedly, this is coarse, and we fully recognize that many other researchers, as well as nonresearchers, engage in what they would also call energy modelling (see ref. ${ }^{6}$ for more detailed descriptions).

The way energy modellers treat, or could treat, extreme events, drivers, and outcomes is determined by how they devise their storylines, then construct their tools to quantify those storylines, and ultimately assess the implications of those storylines. The following observations can be drawn from the existing literature in this area, even if the term 'extreme' is not typically used.

\section{Transient events}


Modellers could, in principle represent transient events; however, in practice this presents a challenge due to the models' generally limited temporal and spatial resolutions. Energy models are characterized by long-term time horizons (out to 2100 or even beyond); a finite number of inter-annual time-steps (every 5 or 10 years); limited intra-annual or intra-day time-slice resolution; and fairly aggregated jurisdictional boundaries (countries / groups of countries, or a collection of sub-national zones). Moreover, many, though not all, models operate under the premise of 'perfect foresight', meaning they optimize over the full model time horizon with complete knowledge of all future parameters at all points in time. While recent advances in model downscaling, temporal resolution, and simulation of myopic decision-making are nowadays helping modellers to surmount some of these hurdles ${ }^{7,8}$, computational limits nonetheless appear to be the constraining factor for some time yet. This is true with respect to both reaching a solution and then the subsequent data-handling required for processing the results.

\section{Disruptive drivers}

Energy modellers are well equipped to represent a range of disruptive drivers over the long term, and in some respects they already do this. As an example, the $1.5^{\circ} \mathrm{C}$ consistent pathways synthesized in the Intergovernmental Panel on Climate Change (IPCC) Special Report on Global Warming of $1.5^{\circ} \mathrm{C}(\mathrm{SR} 1.5, \text { Ch. } 2)^{9}$ robustly show a rapid peak and then decline in global emissions beginning within the next few years, and importantly after nigh on two centuries of continual growth - clearly quite a disruption. Another example is the range of modelled Shared Socio-economic Pathways 
(SSPs), which contains a trend case along with some marked departures from that trend, in terms of social, economic, demographic, political, technological, and behavioural dynamics ${ }^{10}$.

A study illustrating how disruptive drivers can be more broadly considered in modelling is the 'Low Energy Demand' scenario of Gruebler et al. (2018) ${ }^{11}$, which quantitatively articulates a $1.5^{\circ} \mathrm{C}$-consistent pathway that is a striking departure from even the most ambitiously sustainable SSP1. Importantly, that work is quite explicit about the many assumptions on scaling and deployment of new forms of energy service provision (including electrification, sharing, automation, and changes in lifestyle and consumer preferences) that could contribute to the extremely low levels of future energy demand borne out by the modelled pathway. Not all scenario studies are clear about how the myriad assumptions underlying the modelling add up to the energy service demand projections ultimately converged upon. Or, simpler still, modellers will borrow energy service demand projections from existing studies.

\section{Unexpected outcomes}

Energy modellers to date seem to have little appetite for representing unexpected outcomes with their tools; hence, the literature contains precious few examples of such scenarios. Part of this derives from limits to what current-generation models can do, while another part derives from limits to how far current-generation thinking can take the community. All modellers recognize that there is an overt human element to their craft, and we all know that personal views will inevitably influence one's thinking around the 
'what is possible'. But how about the 'what could be'? Fewer modellers engage in this practice of deeper reflection on a regular basis, meaning for each new scenario exercise. Yet, the risk of not doing so is stark, as cognitive biases, whether conscious or subconscious, can prevent a modeller - and by extension their model - from seeing futures that are significantly different from the past ${ }^{12,13}$. (We of course admit our own culpability in this regard.)

There is thus no doubt that many, potentially highly impactful, eventualities are currently being ignored by some of the world's most prominent energy models. What is more, many models lack mechanisms that might lead to the emergence of those eventualities ${ }^{14}$. Put another way, while the degrees of freedom inherent in constructing a scenario narrative are essentially infinite (subject to the laws of physics and time), the capacity and willingness of modellers to articulate the vast space of the unknown and then to quantitatively describe that space with numerical assumptions and sets of equations seems to be far more constrained. Somewhat paradoxically, these constraints arise because of the great pains energy modellers have taken in recent years to enhance the 'realism' of their tools, oftentimes responding to calls from outside the modelling community ${ }^{15}$. Yet, by targeting realism, a concept that is inherently anchored in a consensus perception of the present, modellers risk succumbing too completely to a 'use the here and now to inform the future' kind of mindset, which, in turn, can conflict with modellers' collective responsibility to explore the full colour and depth of future possibilities. At the end of the day, energy modellers play an important 
role in informing the world's decision makers. So, if the modelling tools are themselves overly conservative parametrically and/or too rigid structurally, that role is compromised.

\section{Toward exploring extremes systematically}

Energy modellers construct and apply their tools to meet a variety of generally accepted standards, such as conforming to (current) scientific best practice, providing for users' (current) needs, and surviving the (current) process of peer-review. While such standards and norms are continuously changing, there is, at a given point in time, a reticence among some modellers to deviate too widely from the median or mainstream, perhaps for fear of failing to meet these standards. These kinds of sentiments must be eschewed in favour of pushing the scientific, policy, and business discourse in new directions. If the modelling community is to more adequately inform these conversations by representing future events, drivers, and outcomes that are in one way or another out of the ordinary, then relaxing models' myriad parametric and structural constraints and modellers' deeply-set mental inhibitions should be encouraged, not discouraged.

To this end, we advocate for modellers to think more freely during the critical and highly imaginative brainstorming phase of the scenario-building process, and then to populate their tools with a more vibrant array of assumptions so that explorations of extreme possibilities are not prevented ex-ante. This could include doing something as simple as assuming 'impossibly' high levels of human migration in a given scenario to as involved as allowing (currently) non-mainstream economic constructs to emerge over time based 
on particular pathway dynamics and indicators (for example, a move away from neoclassically-based systems as society approaches certain planetary boundaries). While we of course appreciate that the entire canvas of the scenario space can never be fully explored - and we definitely do not pretend to know all the colours the palette should contain - we also recognize that, because models depend on modellers for their structure and boundary conditions, model-derived pathways can only be as extreme as the modellers themselves allow. And here is where we believe modellers could become more artful and more risky.

One way to surmount the structural limitations of energy models is to do more of the quantitative scenario-crafting outside the confines of the model itself (i.e., not directly within its core code). Such 'off-model' analyses could propel the energy modelling and scenario science community forward as it grapples with the notion of extremes in increasingly sophisticated ways. The scenario analysis of Gruebler et al. (2018) offers one example for how to do this. First, an overarching scenario narrative was interpreted by detailed sectoral decomposition analysis using simple accounting tools, thereby allowing considerably more degrees of freedom to explore the emerging potential of new technologies and business models than would have been the case directly within an energy model, given its encoded and singular view of how the world works. Then, only after quantifications for energy demand out to mid-century were estimated, an energy model was used to solve for the optimal energy supply mix. 
The basic idea with this and other potential recipes for off-model analysis is to introduce a layer of calculations and deliberations in between the scenario storyline (unconstrained ability to explore extremes) and the energy model proper (highly constrained ability to explore extremes). Off-model activities can range from, for example, spreadsheet modelling, statistical analyses and econometrics, to stakeholder engagement and other forms of interactive/participatory methodologies. To be sure, there already exists a broad and under-utilized toolkit from other futures analysis communities (i.e., non-modellers) that could be drawn upon to augment energy modellers' endeavours in this space ${ }^{16}$.

To provide greater clarity on this idea, Table 1 clusters a number of examples of extreme events, drivers, and outcomes in terms of whether current-generation energy models are able to represent them, and then beyond that where off-model analyses could help to further the cause. By our estimation, there is actually quite a lot that current models could already do - or have already done - though in many cases models would need some degree of temporal enhancement to push the scientific frontier beyond today (for example, annual or monthly time-steps that are resolved hourly). Moreover, running models 'myopically' would be necessary for many experiments that attempt to capture surprises (i.e., allowing the model knowledge of only the present and past, but not the future).

Table 1: Energy model capabilities to capture extremes. Examples of types of extremes that could be addressed by models, either endogenously within the model or via off-model analyses. 


\begin{tabular}{|c|c|c|}
\hline & $\begin{array}{c}\text { What energy models can } \\
\text { or could incorporate }\end{array}$ & $\begin{array}{l}\text { What off-model analysis } \\
\text { could help energy } \\
\text { models incorporate } \\
\text { better }\end{array}$ \\
\hline $\begin{array}{l}\text { Transient events } \\
\text { (sudden / short term) }\end{array}$ & $\begin{array}{l}\text { - Rapid diffusion of } \\
\text { technologies over short } \\
\text { interval } \\
\text { - Sudden drop in technology } \\
\text { costs } \\
\text { - Brief periods of very low/high } \\
\text { solar and wind availability } \\
\text { - Temporary power plant } \\
\text { outag es } \\
\text { - Disruptions in energy trade } \\
\text { - Stop-start (volatile) policy }\end{array}$ & $\begin{array}{l}\text { - Politics of countries and } \\
\text { regions } \\
\text { - Migration over brief periods } \\
\text { - Economic boom/bust cycles } \\
\text { - Weather events }\end{array}$ \\
\hline $\begin{array}{l}\text { Disruptive drivers } \\
\text { Unexpected outcomes } \\
\text { (accumulative / long term) }\end{array}$ & $\begin{array}{l}\text { - New waves of social } \\
\text { resistance to particular } \\
\text { technologies } \\
\text { - Very low/high population and } \\
\text { economic development } \\
\text { - Deep structural changes in } \\
\text { the economy (sectoral } \\
\text { contribution to wealth) } \\
\text { - Alternative economic } \\
\text { constructs } \\
\text { - Fundamental changes in } \\
\text { consumer preferences for }\end{array}$ & $\begin{array}{l}\text { - Geopolitical realignment } \\
\text { - Alternative political and } \\
\text { institutional constructs } \\
\text { - Mass automation of work } \\
\text { - Large-scale changes in } \\
\text { migration patterns } \\
\text { - Medical breakthroughs that } \\
\text { transform population age } \\
\text { structure and life } \\
\text { expectancies } \\
\text { - Wholly new energy supply } \\
\text { and end-use technologies and }\end{array}$ \\
\hline
\end{tabular}




\begin{tabular}{|l|l|l|}
\hline & technology & paradigms \\
- Major changes in fossil & - Influence of social activism on \\
resources/reserves & policy \\
- Inability of specific & \\
technologies to continue to & \\
operate under changing & \\
environmental conditions & \\
& & \\
\hline
\end{tabular}

In conducting deeper analyses of extremes off-model, energy modellers would benefit enormously from collaboration with other research communities, including those communities not normally engaged in scenario-building ${ }^{16}$. These collaborations should include both quantitative and qualitative expertise, ranging from, for example, materials scientists and data scientists on one end to sociologists and historians on the other, along with many other disciplines in between. Specifically, energy modellers would do well to leverage the inter-disciplinary strengths of the futures and socio-technical research communities, where a considerable amount of knowledge on people and institutions already exists ${ }^{17,18}$. Modellers could also afford to spend more time working with discipline-specific experts in the areas of transport, buildings, industry, and power systems, in order to learn more about the various possibilities and impossibilities foreseen in each sector.

To close, in an uncertain world that is speeding towards change, possibly disruptive change, analyses of extreme energy futures become all the more important. Energy modellers engaged in the business of crafting long-term scenarios and pathways are 
perhaps best positioned to take on this task, and in fact have already done some work in this space, such as modelling $1.5^{\circ} \mathrm{C}$-consistent pathways and the Shared Socioeconomic Pathways. However, going beyond today's status quo to explore the 'out of the ordinary' requires new thinking, new experiments, and, quite possibly, new combinations of tools, including off-model analyses. This is a tall order to be sure, but there is no risk in trying. Modellers have over time become adept at seeing the forest for the trees; however, in the case of extremes it is those lone trees outside the forest that now deserve a closer look.

\section{References}

1 Farmer, J. D., Hepburn, C., Mealy, P. \& Teytelboym, A. A Third Wave in the Economics of Climate Change. Environmental and Resource Economics 62, 329-357, doi:10.1007/s10640-015-9965-2 (2015).

2 Ma, T., Grubler, A., Nakicenovic, N. \& Arthur, W. B. Technologies as agents of change: A simulation model of the evolving complexity of the global energy system. IIASA Interim Report: IR-08-021 (International Institute for Applied Systems Analysis, Laxenburg, Austria, 2008).

3 Marang oni, G. et al. Sensitivity of projected long-term CO2 emissions across the Shared Socioeconomic Pathways. Nature Climate Change 7, 113, doi:10.1038/nclimate3199 (2017).

4 Smith, M. D. An ecological perspective on extreme climatic events: a synthetic definition and framework to guide future research. Journal of Ecology 99, 656-663, doi:10.1111/j.13652745.2011.01798.x (2011).

5 Albeverio, S., Jentsch, V. \& Kantz, H. Extreme Events in Nature and Society. (Springer, 2006).

6 Sathaye, J. \& Shukla, P. R. Methods and Models for Costing Carbon Mitigation. Annual Review of Environment and Resources 38, 137-168, doi:10.1146/annurev-environ-083111-092115 (2013).

7 Riahi, K. et al. Locked into Copenhagen pledges - Implications of short-term emission targets for the cost and feasibility of long-term climate goals. Technological Forecasting and Social Change 90, 823, doi:10.1016/j.techfore.2013.09.016 (2015).

8 Blanford, G. J., Merrick, J. H., Bistline, J. E. T. \& Young, D. T. Simulating Annual Variation in Load, Wind, and Solar by Representative Hour Selection. The Energy Journal 39, doi:10.5547/01956574.39.3.gbla (2018).

9 Rogelj, J. et al. in Global Warming of $1.5^{\circ} \mathrm{C}$ : an IPCC special report on the impacts of global warming of $1.5^{\circ} \mathrm{C}$ above pre-industrial levels and related global greenhouse gas emission pathways, in the context of strengthening the global response to the threat of climate change, sustainable development, and efforts to eradicate poverty (eds G. Flato, J. Fuglestvedt, R. Mrabet, \& R. Schaeffer) 93-174 (IPCC/WMO, 2018).

10 O'Neill, B. C. et al. A new scenario framework for climate change research: the concept of shared socioeconomic pathways. Climatic Change 122, 387-400, doi:10.1007/s10584-013-0905-2 (2014). 
11 Grubler, A. et al. A low energy demand scenario for meeting the $1.5^{\circ} \mathrm{C}$ target and sustainable development goals without negative emission technologies. Nature Energy 3, 515-527, doi:10.1038/s41560-018-0172-6 (2018).

12 Mullally, S. L. \& Maguire, E. A. Memory, Imagination, and Predicting the Future:A Common Brain Mechanism? The Neuroscientist 20, 220-234, doi:10.1177/1073858413495091 (2014).

13 Tversky, A. \& Kahneman, D. Judgment under Uncertainty: Heuristics and Biases. Science 185, 11241131, doi:10.1126/science.185.4157.1124 (1974).

14 Gambhir, A. Planning a Low-Carbon Energy Transition: What Can and Can't the Models Tell Us? Joule 3, 1795-1798, doi:10.1016/j.joule.2019.07.016 (2019).

15 IRGC. Assessment of future energy demand: A methodological review providing guidance to developers and users of energy models and scenarios. (International Risk Governance Council, Lausanne, Switzerland, 2015).

16 Gambhir, A., Cronin, C., Rogelj, J. \& Workman, M. Using futures analysis to develop resilient climate change mitigation strategies. (Grantham Institute, Imperial College London and ClimateWorks, 2019).

17 Köhler, J., Turnheim, B. \& Hodson, M. Low carbon transitions pathways in mobility: Applying the MLP in a combined case study and simulation bridging analysis of passenger transport in the Netherlands. Technological Forecasting and Social Change, 119314, doi:10.1016/j.techfore.2018.06.003 (2018).

18 Turnheim, B. et al. Evaluating sustainability transitions pathways: Bridging analytical approaches to address governance challenges. Global Environmental Change 35, 239-253, doi:10.1016/j.gloenvcha.2015.08.010 (2015). 